\title{
POR QUE OS ESTUDANTES DA EDUCAÇÃO BÁSICA EXPLORAMPOUQUISSIMAMENTE OS DICIONÁRIOS DE LÍNGUAS?
}

\author{
Marcelo Sabino Luiz*
}

\begin{abstract}
RESUMO: Os estudantes da educação básica sabem explorar apropriadamente os recursos do dicionário? O propósito desse estudo consiste em responder a essa questão, ao destacar as razões que impedem os aprendizes de adotarem potencialmente o dicionário enquanto fonte de pesquisa nas atividades de recepção e de produção de linguagem na escola. Em resposta ao problema enunciado, este artigo aponta três fatores que determinam o insuficiente aproveitamento do dicionário em sala de aula pelo aluno, e tem como base as evidências do estudo proposto por Sabino Luiz (2019), que destacou, a saber: (i) a ausência de proficiência lexicográfica, (ii) o uso indiscriminado do material lexicográfico pelo aluno e (iii) a vaga mobilização docente frente às práticas didáticas. Diante de tais constatações de natureza bibliográfica, neste trabalho mobilizamos reflexões acerca da necessidade de se proceder ações pedagógicas voltadas para práticas de letramentos e de educação lexicográfica escolar. Assim, no intento de responder a tais provocações, nos baseamos nos princípios do quadro teórico da Lexicografia Pedagógica (LP).
\end{abstract}

PALAVRAS-CHAVE: Pedagogia lexicográfica; Prática lexicográfica escolar; Prática indiscriminada.

\section{Introdução}

A Lexicografia Pedagógica - é uma disciplina para a qual no âmbito dos estudos linguísticos - almeja oferecer os parâmetros tanto teórico-críticos quanto práticos para a compilação e a elaboração de dicionários com propósitos e fins pedagógicos. Desde meados do século XX, a LP, assim como é popularmente chamada, dedica-se a produzir obras de referências que permitam promover a cultura lexicográfica escolar, bem como a oferecer aos professores em serviço diferentes tipos de materiais didáticos a serem utilizados como instrumentos de apoio no processo de ensino e de aprendizagem.

Com esse objetivo a LP procura difundir no modelo atual da didática de ensino, a ideia de que os dicionários de aprendizagem cumprem com um importante papel pedagógico e quando são devidamente compilados a determinados grupos de usuários que se encontram em processo de aquisição da língua escrita, tais obras pedagógicas possibilitam o

* Doutorando em Estudos Linguísticos pela Universidade Estadual Paulista (Unesp), Campus de São José do Rio Preto. Mestre em Letras pela Universidade Estadual do Norte do Paraná (Uenp). 
desenvolvimento de competências 'linguageiras’ específicas dos usuários-aprendizes. Essas competências são linguísticas e discursivas e que englobam várias competências curriculares prescritas em documentos oficias de ensino de línguas que, em geral, demandam sobretudo a compreensão, a produção escrita e a reflexão sobre o uso da língua.

Além de configurar como artefato cultural, histórico e produto comercial, o objeto lexicográfico (dicionário) armazena funções eminentemente pedagógicas, que são capazes de auxiliar os aprendizes em situações de dificuldades com o uso da língua e que exigem habilidades linguísticas. Em particular, tais quais são associadas ao domínio do conhecimento lexical, como as colocações, o domínio de propriedades morfológicas de palavras, aspectos semânticos e pragmáticos do léxico. Esses domínios mobilizam o uso de dicionários e recaem sobre eles predominantes prerrogativas pedagógicas.

Evidencia-se, portanto, que um dicionário para aprendizes, de qualidade, deve se proceder de técnicas lexicográficas específicas, já que são muitos os níveis e as necessidades linguísticas dos estudantes ao longo da Educação Básica (BUGUEÑO MIRANDA, 2005). Assim, o protótipo da obra lexicográfica desenhada a fins pedagógicos precisa obedecer a parâmetros metodológicos consistentes dado que cada componente informativo do dicionário é direcionado a um determinado público alvo em questão e é, desse modo, proposto a efeito de atender os anseios linguareiros dos falantes em torno do léxico geral, em aspectos diversos do sistema linguístico: fonéticos, morfológicos, pragmático- discursivos, sintáticos e sociolinguísticos.

Concebendo o objeto lexicográfico com tais características didáticas - que ajudaria o usuário na aprendizagem de um idioma - e dada a complexidade estrutural do dicionário de aprendizagem, pressupomos que o leitor em potencial dessa obra necessita igualmente possuir habilidades específicas de uso que partiriam desde o reconhecimento sobre o modo de saber manipular o instrumento, até o meio de aproveitar as informações contidas no escopo da obra. Diante dessa concepção que tomamos a respeito do uso de dicionários, acreditamos que o texto lexicográfico jamais deve ser considerado uma tarefa de fácil compreensão, como é comumente feito em sala de aula. Longe disso, ele deve ser tomado como objeto a ser instrumentalizado para fim de auxiliar os alunos a superarem os desafios reais 
dos "usos linguísticos" em situações escolares ou próprias da vida social.

Frente a um paradoxo instalado na nossa realidade educacional brasileira, o objetivo desse trabalho consistirá em levantar, ao menos a plano de discussão, fatores que tendem a impactarem de modo negativo o uso de dicionários em sala de aula. Pressupomos, em nossos vieses, que o mau uso dessa ferramenta pelo aluno em situações de dificuldades linguísticas, em sala de aula - e quando feita de modo indiscriminado pelo professor -, pode levar o estudante a não explorar adequadamente os recursos informativos deste material didático, isto é, limitando-os a utilizar enquanto fonte de investigação sobre fatos linguísticos diversos. Para provocar essa discussão fundamentaremos nos princípios gerais da Lexicografia Pedagógica.

\section{O desenvolvimento de competências em linguagem e o uso de dicionários de línguas}

Segundo Oliveira (1993), é a partir do uso de instrumentos (materiais didáticos, livros etc.) nas atividades da vida social enquanto ferramenta semiótica para compreender o mundo que o homem se marca enquanto uma espécie humana diferenciada de todas as outras existentes. De tal modo, nesta atividade simbólica de linguagem que o distingue dos diferentes seres biológicos existentes se justifica em razão dos objetivos de que o homem se valem dos objetos semióticos do mundo, em sua relação com o meio biológico, o social e o cultural; já que ele, o homem, utilizam desses instrumentos não apenas para sua sobrevivência humana, mas como ferramenta de trabalho.

Os instrumentos de mediação classificam-se, segundo Vygotsky (1989), em 'instrumentos materiais' e em 'instrumentos psicológicos'. Segundo o teórico, os instrumentos materiais são elementos físicos e, portanto, encontram na realidade externa ao indivíduo, assim, por se encontrarem fora das estruturas mentais do homem "[...] suas funções são provocar mudanças nos objetos, controlar processos de natureza física" (OLIVEIRA, 1993, p. 30) - como na busca de uma informação no dicionário quando se quer resolver uma dúvida qualquer sobre alguma palavra. Dá-se então, a concluir, que a função dos instrumentos materiais, 'materiais linguísticos', será de desenvolver competências de linguagem 
dos falantes de uma língua, uma vez que servem como elementos de mediação ao desenvolvimento cognitivo.

Os dicionários se destacam, dessa maneira, como 'instrumentos materiais', e quando postos em direto contato com o ensino da língua materna ou de línguas estrangeiras terão o efeito de provocar interferências significativas no processo de ensino e de aprendizagem, potencializando o desenvolvimento das funções psíquicas superiores dos aprendizes, bem como o alargamento das capacidades de compreensão, de produção, de análise e de reflexão linguística.

Esse processo de expansão cognitiva do conhecimento, seria, portanto, constantemente diante à consulta aos dicionários, quando em uma dúvida qualquer o aprendiz tem acesso ao elemento mediador das ações psicológicas do homem, o léxico - o elemento estruturador do saber humano.

Os instrumentos lexicográficos são elementos materiais para a tradução semiótica de aspectos simbólicos do léxico, pois, de fato, ajudam os aprendizes a fixarem os mecanismos linguísticos e gramaticais necessários à apropriação do léxico oral (língua falada) e do léxico escrito (língua escrita). Nesse sentido, os recursos dos dicionários não servem apenas como instrumentos materiais ao desenvolvimento das funções cognitivas, mas servem como depositórios dessas ações cognitivas do homem, porque catalogam de maneira sistemática os signos lexicais de uma cultura, e com isso os hábitos e os modos de ser e utilizar a língua de uma determinada comunidade.

Dentre as competências linguísticas das quais os documentos oficiais de aprendizagem (Base Nacional Comum Curricular - BNCC, Parâmetros Curriculares Nacionais PCN, bem como outros documentos oficiais) prescrevem a serem desenvolvidas nos estudantes da Educação Básica, e conforme acreditamos que os dicionários permitiriam auxiliar o desenvolvimento do aprendizado de línguas, destaca-se: a competência de compreensão linguística de textos e a competência de produção de textos.

As obras lexicográficas destinadas a fins escolares, assim quando vistas enquanto ferramentas didáticas auxiliares para o desenvolvimento das faculdades de competências em linguagem dos aprendizes, aspiram a resolverem as dúvidas quanto ao uso da língua 
dos aprendizes em diferentes situações comunicativas da vida pública e escolar. Entendemos que no contexto pedagógico essas funções atribuídas às obras lexicográficas estarão intrinsecamente atreladas às demandas curriculares, às diferentes motivações de consultas dos usuários e ao potencial perfil do consulente.

Como descreve Tarp (2006, p. 297), os dicionários voltados a objetivos pedagógicos são "[...] ferramentas de uso concebidas para satisfazer tipos específicos de necessidades que apresentem tipos específicos de usuários em tipos específicos de situações”. Dessa forma, os dicionários de aprendizagem se classificam como obras rigorosamente funcionais. $\mathrm{O}$ conjunto de cada segmento agregado em sua 'macroestrutura' e 'microestrutura' enquadram um ideal seletivo programa de informações úteis às necessidades e às habilidades de consulta de cada grupo de usuários. Neste ponto, conforme corroboramos com Bugueño Miranda (2005), o aspecto qualitativo de um dicionário não se restringe apenas na totalidade de dados léxicos dispostos no escopo de cada obra, mas na utilidade funcional de que o dicionário se oferece a um determinado potencial grupo de usuários, em processo de aprendizagem.

Embora os dicionários reúnam um certo conjunto de segmentos informativos relevantes a qualquer grupo de usuários, como os mais usuais: os significados, os sinônimos, os antônimos e a ortografia de palavras. Ademais, enquadram informações muito heterogêneas sobre o léxico e que são similarmente válidas para alguém que está aprendendo uma língua. No entanto, tais informações são ignoradas muitas vezes pelos usuários, e poucas vezes aproveitadas devido à pouca educação lexicográfica dos aprendizes. Ressaltamos, entre outras, como informações pouco aproveitadas as abreviações; as marcas de usos; e as indicações fonéticas, sintáticas, pragmática-discursivas e etimológicas.

A respeito das funcionalidades didáticas do material lexicográfico, Hausmann (1977) isola doze tipos de informações léxicas registradas nos dicionários de línguas, que podem, segundo ele, cobrir às necessidades dos usuários e proporcionar rico aprendizado do idioma - neste caso, aos consulentes em processo de aprendizagem. Para Hausmann (1977) para se ampliar o repertório de competências em linguagem com uso de dicionários, algumas notações lexicográficas devem ser discriminadamente consideradas, como: 
i. Informações diatópicas - notações explicativas quanto às variações linguísticas motivadas por fatores geográficos, ou seja, uso de palavras ou expressões regionalistas, como os casos de africanismos, americanismos etc;

ii. Informações diatécnicas - notações explicativas quanto à área de especialidade e terminológica de determinados itens lexicais;

iii. Informações diastráticas - notações explicativas quanto às variações de registros de itens lexicais em decorrência do nível social e contextos empregados, isto é, informam quando usados como gíria, uso popular, familiar etc.;

iv. Informacões diacrônicas - notações explicativas quanto à mudança linguística dos itens lexicais ao longo do tempo, ou seja, quando a palavra é um arcaísmo, um neologismo, um termo antiquado, outros;

v. Informações diaintegrativas - notações explicativas para informar quando os itens lexicais são estrangeirismos ou idiomatismos;

vi. Informacões diafrequentes - notações explicativas para indicar a frequência e intensidade de emprego de determinada palavra em certos contextos, ou seja, quando for de uso comum, raro ou muito raro;

vii. Informações diamediais - notações explicativas para distinguir a modalidade de uso dos itens lexicais, quando empregado na modalidade da língua oral ou na modalidade da língua escrita;

viii. Informações difásica - notações explicativas que revelam os níveis de linguagem dos itens lexicais, ou seja, se os itens são próprios da norma do português padrão culto ou quando variante desta.

ix. Informacões diatextuais - notações explicativas que indicam se a palavra é restrita a determinado gênero textual, por exemplo, da esfera acadêmica, jornalística, esportiva, literária etc.;

x. Informações dianormativas - notações explicativas que indicam se determinados itens lexicais estão em desvios da norma-padrão;

xi. Informações diaevaluativas - notações explicativas que expressam o comportamento e a atitude do falante quanto ao uso de determinado item lexical, por exemplo, é empregado com polidez, com eufemismo, figurativamente, de modo vulgar, de modo pejorativo etc.

Como se percebe, os dicionários pedagógicos podem cobrir inúmeras das dificuldades dos estudantes no trânsito do processo de aprendizagem escolar tais como estão englobados conhecimentos e competências lexicais que, enfim, demandam a reflexão e a análise 
do próprio exercício da atividade de linguagem. O dicionário pretende a equacionar e a responder ao mesmo tempo, a um leque de necessidades comunicativas que abrangem:

a) Compreensão linguística: ao atribuir exemplos nos verbetes auxiliam os utentes a perceberem os fenômenos semânticos e pragmáticos provenientes do emprego do léxico. Oferecem diferentes significados dos vocábulos e demonstram os empregos adequados das palavras nos contextos usuais, desse modo, ajuda o usuário durante a tarefa de compreensão e reflexão em torno de efeitos de sentidos de palavras decorrentes de seleções textuais.

b) Expressão escrita: ao indicar informações ortográficas e gramaticais, ajuda o estudante na aquisição da língua escrita, favorecendo o estudante a consolidar o sistema alfabético ortográfico e o domínio progressivo das convenções da escrita, bem como de outros aspectos da língua (sintáticos, semânticos e pragmáticos).

c) Expressão oral: ao indicar informações relacionadas à pronúncia das palavras e das suas variações fonéticas, ajuda o usuário identificar os falares dialetais do português brasileiro (quando tratar de dicionários monolíngues), assim como reconhecer propriedades de irregularidades ortográficas decorrentes da não correspondência letra-som dos vocábulos, proporcionado, em sala de aula, o exercício da reflexão sobre os fenômenos da oralidade e da mudança linguística.

d) Análise e reflexão linguística: ao indicar com marcações explicativas o nível de linguagem dos itens lexicais, os dicionários advertem o usuário quando os usos são provenientes da linguagem formal ou informal. Essas marcações apontam as possíveis variantes adequadas a cada contexto e situação de comunicação a serem utilizadas em determinados gêneros de texto. Além de que, registram os fenômenos semânticos e as possibilidades de significados das palavras, o grau de especialidade etc. Tais marcações lexicográficas, convidam o aluno em sala de aula, bem como o próprio professor a refletirem sobre os mecanismos da nossa língua e desenvolverem sua competência lexical.

e) Dominio do vocabulário: o universo léxico do dicionário, isto é, o número total de palavras contribui para a aquisição de capital léxico pelo estudante e, em consequência, o desenvolvimento da competência comunicativa.

Em virtude da gama de informações ofertadas de maneira didática pelos dicionários pedagógicos aos aprendizes, é quase que incabível a didática de línguas relegar a ele fonte de utilidade de mera consulta eventual. Esses materiais didáticos, certamente, precisam estar sob às carteiras dos estudantes da Educação Básica todos os dias, em todas as situações de 
produção e de recepção de linguagem. Isso porque, não é exclusivamente sobre os significados e a ortografia de palavras de que se ocupa esses materiais, mas, a respeito de: diversos fatos e fenômenos de funcionamento da língua/linguagem; aspectos pragmático- discursivos e ideológicos dos usos linguísticos, condições sociolinguísticas dos falantes; e, em particular, a história e a cultura do povo. Saberes estes, que, para nós, figuram-se como essenciais para o desenvolvimento das competências linguageiras dos estudantes, assim como ao atendimento dos conhecimentos prescritos pelos documentos oficiais de aprendizagem.

Passaremos adiante a definir os fatores que, supostamente, conduzem o trabalho pedagógico docente para o uso indiscriminado e pouco satisfatório do dicionário por alunos do ensino básico. A nosso ver, tais fatores estão enraizados na prática de ensino do professor em serviço.

\section{Falta de proficiência lexicográfica}

Muitas vezes, o uso de dicionários aparenta ser uma tarefa ligeiramente fácil a qualquer pessoa, isto é, basta apenas abri-los que encontraremos à palavra ou à informação desejada: não é isso?

Este conceito reducionista de dicionário - que ele nos serve apenas para tirar dúvidas eventuais - nos leva a nossa primeira provocação, a que o uso proficiente e frequente do dicionário na escola quase nunca se torna alvo de tema de preocupação na didática de ensino do português ou de línguas adicionais, uma vez que se tem, no imaginário educacional, uma ideia pobre e minimalista sobre a estrutura e os recursos didáticos de diferentes categorias de dicionários.

Para mostrar que tal prática não é uma atividade escolar desmerecedora de treinamento e de desenvolvimento de habilidades, embora às vezes nos possa parecer, e ainda como geralmente perpetuam alguns livros didáticos e velhas práticas. Tomaremos adiante algumas evidências da pesquisa de Sabino Luiz (2019), a qual buscou, a partir de testes a dezessete participantes de uma escola pública, propor em sala de aula uma abordagem de letramento para a apropriação de habilidades lexicográficas e por consequência disso, enten- 
der a relação entre o nível de competência do usuário-aprendiz do dicionário e a aprendizagem da língua materna.

Conforme conclusões do autor, nos achados da sua pesquisa, o perfil inicial de proficiência dos estudantes ante à educação lexicográfica na escola era totalmente deficitário. De acordo com Sabino Luiz (2019) os alunos contavam com obras lexicográficas monolíngues na sala de aula, porém, os usos geralmente ocorriam indiscriminadamente, de modo que o consulente escolar embora os utilizassem para obterem informações precisas sobre as palavras, não sabiam muito bem usufruírem detidamente das propriedades informativas do instrumento lexicográfico em mãos, das funcionalidades de cada uma dessas propriedades e de outras características salientes das obras consultadas. Desta forma, limitavam esse uso restritivamente a consulta de significados e ortografias de palavras em detrimento de outros segmentos relativamente importantes. Além disso, o autor relata que a falta de clareza e de discriminação por parte dos alunos participantes do estudo, sobre os diferentes tipos de dicionários utilizados por eles durante a busca de uma informação desejada, quase sempre os conduziam ao acesso de informações inapropriadas ao ano série e a idade.

Ressaltam os Parâmetros Curriculares Nacionais que

A consulta ao dicionário pressupõe conhecimento sobre as convenções da escrita e sobre as do próprio portador: além de saber que as palavras estão organizadas segundo a ordem alfabética (não só das letras iniciais mas também das seguintes), é preciso saber, por exemplo, que os verbos não aparecem flexionados, que o significado da palavra procurada é um critério para verificar se determinada escrita se refere realmente a ela, etc. Assim, o manejo do dicionário precisa ser orientado, pois requer a aprendizagem de procedimentos bastantes complexos. (BRASIL, 1997, p. 87)

Nota-se, por sua vez, conforme destacam os PCN e segundo conformam os dados em Sabino Luiz (2019) que, a ausência de agilidade e de automação interferem no aproveitamento da consulta lexicográfica pelo utente. Aliás, destacam-se duas consequências dada a falta de competência dos usuários de dicionários em ambiente escolar que, de acordo com Sabino Luiz (2019), a primeira é, que no momento inicial eles desistem da tarefa antes mesmo de consultar o material didático por darem conta que a atividade será muito complicada e nada 
prazerosa; a segunda, quando alternativamente decidem a persistirem na tarefa de consulta, terminam por consultá-lo de maneira indiscriminada, pois não sabem como e onde poderão tirar às vantagens necessárias do material para obterem um melhor aproveitamento face às dificuldades com a língua. Sobre esse último aspecto, discutiremos com detalhes adiante.

\section{O uso indiscriminado}

Os diferentes materiais lexicográficos distribuídos às escolas são obras polivalentes ou polifuncionais, isso porque visam atender as inúmeras necessidades de linguagem de um público alvo específico, respeitando as habilidades que os asseguram a tirarem às vantagens de seus recursos. Por exemplo, um dicionário do tipo $2^{1}$ voltado a alunos das séries inicias do Ensino Fundamental I, não poderá em qualquer hipótese conter informações complexas e desnecessárias para esse grupo de usuários, sob risco de elas se tornareminúteis.

Para usufruir dos benefícios do material lexicográfico é imprescindível que o consulente saiba que a obra que está a sua disposição se organizará sob a intersecção de três estruturas básicas de acesso.

De uma 'macroestrutura', que é constituída em geral pela totalidade de segmentos informativos do dicionário e o escopo léxico da obra, recortando-se em formas de verbetes, em duas colunas verticais que sistematizam os itens léxicos em ordem alfabética. De uma 'microestrutura', um texto interno a 'macroestrutura', que dá sustentação sobre diversas informações acerca das palavras do dicionário, sempre a partir de um comentário de forma e um comentário semântico da palavra em questão (ver tal assunto em discussão em BUGUEÑO MIRANDA, 2005). De uma 'medioestrutura', que remetem às informações de uma parte do verbete a outras partes do dicionário ou a outros verbetes.

Nos faz sentido admitir que o desconhecimento pelo usuário sobre o programa de informações linguísticas do dicionário e o modo de funcionamento de cada propriedade da

${ }^{1}$ Tipo 2 - Denominação adotada pela Comissão de Avaliação do Ministério da Educação e Cultura para classificar a série de tipologias de dicionários escolares distribuídos pelo Programa Nacional do Livro Didático (PNLD), 2012. 
obra, poderá contribuir para a insatisfatória performance lexicográfica escolar do aprendiz.

O uso competente do dicionário escolar envolve saber discriminadamentereconhecer e acessar cada conjunto de informações por ele ofertado. Discriminar é diferenciar as partes, é mensurar e identificar sinais gráficos lexicográficos, é processar a leitura do layout do texto da obra dicionarística nos termos de sua usabilidade, ou seja, saber que tal informação é colocada neste espaço e, portanto, estará a serviço de resolver uma dúvida ou um propósito comunicativo.

Para desenvolver tais competências lexicográficas importantes para um bom aproveitamento do dicionário, não será necessário que o aluno decore extensas terminologias da teoria lexicográfica, basta que a escola promova práticas que proporcionem experiências significativas de manejo. Porém, cabe ao professor em serviço, em especial, a dominar e a transpor esses conhecimentos lexicográficos segundo as aptidões e as habilidades linguísticas dos estudantes, procurando orientá-los quanto as tipologias de dicionáriosconsultadas.

Tal asserção, lança-nos a nossa última provocação desse artigo sobre os motivos reais dos estudantes não usarem com frequência e proficientemente os dicionários nas atividades de linguagem, que, em conclusão, recaem nas práticas docentes e revelam uma questão preocupante atualmente, a formação do professor.

\section{As insuficientes práticas docentes para o desenvolvimento da competência lexico- gráfica}

Para Krieger (2005), apesar do reconhecimento unânime das funções didáticas do dicionário o professor “[...] não está aparelhado para explorar a riqueza de informações linguísticas constantes no dicionário e tampouco recebe orientações para escolher o dicionário mais apropriado a seu projeto pedagógico” (KRIEGER, 2005, p. 101). Como destaca, a educação lexicográfica é uma atitude cara ao professor de língua materna principalmente, pois a formação inicial e continuada docente não lhe prepara teórica ou metodologicamente para lidar com as situações de usos envolvendo os diferentes tipos de objetos lexicográficos disponíveis nos acervos bibliográficos da escola e disponíveis no mercado. 
Uma das questões que conformam o uso indiscriminado e que desafiam a competência do utente escolar, é a vaga mobilização didática do professor com o uso de dicionários enquanto ferramentas para o ensino da língua portuguesa, para o processo da alfabetização e para o ensino de outras línguas. Supõe-se que toda essa escassa mobilização docente procede da falta de conhecimentos lexicográficos do professor.

Como é possível observar em dados da pesquisa de Sabino Luiz (2019), a concepção equivocada e o conhecimento minimalista do professor sobre os meios didáticos e os recursos do dicionário tendem a converter a prática lexicográfica pedagógica em mera consulta de palavras e significados, como se o dicionário não pudesse garantir outros propósitos didáticos mais sofisticados quando conjugado às práticas de compreensão, escrita, revisão, tradução e análise linguística. $\mathrm{Na}$ análise dos questionários da pesquisa de Sabino Luiz (2019) concluiu-se a partir das respostas dos sujeitos participantes, que a maioria dos professores da escola não sabiam adequadamente orientar os estudantes por não saberem de que forma poderiam ajudá-los - talvez por não terem métodos adequados e devida formação - a explorar o dicionário nas diferentes situações do dia a dia em sala de aula, bem como a reconhecer os diferentes tipos e como utilizar as propriedades informativas a cada necessidade de consulta.

Tal como é verificável, professores e alunos se encontram despreparados e com falta de formação para utilizarem os dicionários, mesmo diante as ações das políticas públicas de oferta gratuita de dicionários nas escolas, como destaca o Programa Nacional do Livro Didático (PNLD): Dicionários em Sala de Aula.

De fato, ainda há muito a se investigar sobre os possíveis caminhos da didática de línguas para aplicação de projetos políticos voltados a pedagogia lexicográfica nas escolas brasileiras. Nesse cenário, de um lado se justifica o currículo universitário deficiente com falta de disciplinas de Lexicografia e Lexicologia, em nível de graduação e de pós-graduação; de outro lado encontramos a precarização de princípios e de métodos didáticos escolares que promovam práticas de letramentos para o uso e com base em dicionários. 


\section{Considerações finais}

Como sabemos é no dicionário em que podemos ter certa referência, mesmo que parcial, da dimensão de toda essa nossa atividade de produção linguageira humana. O dicionário é o nosso termômetro de uso da língua oral e da língua escrita, já que afere nossa evolução sociocultural. Acreditamos que a escola não deveria afastar o estudante deste material, tampouco negligenciá-lo em sala de aula, pois corre risco de impossibilitar o aluno de se apropriar de um bem valioso da cultura, o léxico da língua.

Neste artigo, procuramos sobretudo tratar sobre a falta de proficiência lexicográfica do aluno e do professor em sala de aula quando associada ao uso indiscriminado do dicionário. Concluímos que ao negligenciar na didática de ensino da língua a prática lexicográfica proficiente, o professor em serviço corrobora com o cenário precário no que diz respeito a utilização proveitosa de dicionários.

Entende-se que os estudantes da Educação Básica não sabem explorar apropriadamente os dicionários escolares devido a esses diversos fatores elencados neste trabalho. É imperativo ponderar que em nosso propósito de estudo não quisemos resolver toda a problemática envolvida nesta questão de precarização docente - até porque isso envolveriam muitas outras discussões -, mas nos detivemos a tentar abrir caminhos para possíveis reflexões na construção de políticas públicas em educação lexicográfica que estreitassem diálogos entre a formação docente, a escola e a produção de dicionários de aprendizagem.

Para finalizar, ressalta-se que as práticas pedagógicas de professores para a utilização de dicionários em sala de aula concentram desafios no tocante a transformar o estado atual da prática lexicográfica escolar dos aprendizes, que como discutimos, pouco tem sustentado na noção de que o dicionário é um instrumento didático complementar, de alto potencial para explorar os usos linguísticos da língua. Nas muitas escolas em nosso país, muitas vezes esse uso indiscriminado pode ser observado pela falta de competência lexicográfica do professor, assim como do próprio aluno. 


\section{WHY DO STUDENTS OF BASIC EDUCATION EXPLOIT VERY LITTLEA LANGUAGE DICTIONARY?}

ABSTRACT: Do students of basic education know how to explore the resources of the dictionary? The objective of this work is to answer this question and highlight as reasons that hinder learning in a potential or dictionary way as a source of research in the activities of reception and production of language. In response to the exposed problem, this article points out three factors that determine the low use of the dictionary in the student's classroom, as reported in the analysis of the study analyzed by Sabino Luiz (2019), a saber: (i) a lexicographic deficiency proficiency; (ii) indiscriminate use of lexicographic material by the student and (iii) vacancy for teaching mobilization in the face of didactic practices. In view of these bibliographic findings, he defends the need for pedagogical actions aimed at teaching and lexicographic education, based on the principles of the theoretical framework of pedagogical lexicography (LP).

KEYWORDS: Lexicographic pedagogy; School lexicographic practice; Indiscriminate use.

\section{REFERÊNCIAS}

BRASIL. Parâmetros Curriculares Nacionais: $1^{\circ}$ e $2^{\circ}$ ciclos do Ensino Fundamental: Língua Portuguesa. Brasília/DF: MEC/SEF, 1997.

BUGUEÑO MIRANDA, F. V. O que o professor deve saber sobre a nominata do dicionário da língua. Revista Língua \& Literatura, v.6/7, n.10/11, 2005. p.17-31.

HAUSMANN, F. J. Einführung in die Benutzung der neufranzosichen Worterbücher. Tübingen, 1977.

KRIEGER, M. G. Dicionários para o ensino da língua materna: princípios e critérios de escolha. Revista língua \& literatura (IMPRESSO), v. 10/11, p. 101-112, 2005.

OLIVEIRA, M. Vygotsky: aprendizado e desenvolvimento, um processo histórico. São Paulo: Scipione, 1993.

SABINO LUIZ, M. Letramento lexicográfico: o dicionário no ensino do léxico e o potencial didático para a inscrição do aluno no mundo da escrita. 2019. 290 f. Dissertação (Mestrado Profissional em Letras) - Universidade Estadual do Norte do Paraná (UENP), Cornélio Procópio. 2019.

TARP, S. Lexicografía de aprendizaje. Cadernos de Tradução, Florianópolis, v. 2, n. 18, p. 295-317, abr. 2006.

VYGOTSKY, L. S. A formação social da mente. São Paulo: Martins Fontes, 1989.

Recebido em: 19/04/2020.

Aprovado em: 22/05/2020. 